\title{
Laz positional verbs: semantics and use with inanimate Figures*
}

\author{
SILVIA KUTSCHER AND N. SEVIM GENÇ
}

\section{Abstract}

In this article, we discuss the meaning and use of positional verbs in the South-Caucasian language Laz. Positional verbs are defined as those verbs which — in combination with one of several locational verbal prefixes (preverbs) - may appear in the basic construction that functions as an answer to a "where" question, the so-called basic locative construction (BLC). Within this class of verbs, we pay particular attention to those positionals which are used regularly in our data to describe the configuration of inanimate movable objects. Laz is shown to be a multiverb language, i.e., a language that uses a comparatively large set of verbs in the BLC. The fourteen verbs in question are $P R V$-dgun 'stand', $P R V$-ren 'stand', $P R V$ zun 'lie', $P R V$-xen 'sit, stay', $P R V$-byun 'be located as mass', $P R V$-mpiy 'be spread', $P R V$-sun 'be smeared', $P R V$-tun 'cover', $P R V$-bun 'hang', $P R V$-nzoy 'stick, be stuck', $P R V$-ntun 'be dipped', $P R V$-çabun 'stick to, be sticky', $P R V$-korun 'be bound', $P R V$-gzun 'burn'. The semantics and the use of these verbs are described in some detail including nontypical configurations, which trigger variation among speakers due to alternative categorizations and prototype effects.

\section{Introduction}

This article deals with the semantics of those positional verbs that are used to describe the location of inanimate movable objects in Laz in a construction identified as the Basic Locative Construction (BLC) in this issue. As a sister language of Georgian spoken on the southeastern coast of the Black Sea, Laz is the only member of the South Caucasian family which is spoken primarily outside of Georgia. The vast majority of its speakers live in Turkey and are bilingual. Laz is a severely endangered 
language. While most Laz older than forty are competent speakers of the language, an increasing number of young Laz are fluent only in Turkish with a rapid decline of language competence with ethnic Laz younger than twenty. In addition, native speakers of Laz restrict the use of their mother tongue to private communications amongst friends and family members. ${ }^{1}$

The variety of Laz under examination in this article is the one spoken in the city of Ardeşen and the villages of the Ardeşen region. In ArdeşenLaz, as in the other Laz dialects, there is a general locative/copula verb on 's/he/it is'. ${ }^{2}$ Wherever possible, however, speakers of Ardeşen-Laz use one of a set of fourteen verb roots in combination with several locational verbal prefixes (preverbs) to identify the position of an inanimate Figure. The verbs are as follows: PRV-dgun 'stand', PRV-ren 'stand', PRV-zun 'lie', PRV-xen 'sit, stay', PRV-byun 'be located as mass', PRVmpiy 'be spread', PRV-sun 'be smeared', PRV-tun 'cover', PRV-bun 'hang', PRV-nzoy 'stick, be stuck', PRV-nťun 'be dipped', PRV-çabun 'stick to, be sticky', PRV-ǩrun 'be bound', PRV-gzun 'burn'. In the following sections, we will identify the conditions under which each of these roots is used. It will become evident that Laz exhibits the characteristics of a multiverb language in the typology given in the introduction to this issue in that the use of each of the positional roots is determined by the perceived Figure-Ground relation, i.e., a nominal whose referent can hold more than one Figure-Ground relation can occur with more than one positional.

The data presented in this article come from a fieldwork stay in the region of Ardeşen in August 2000, ${ }^{4}$ where four speakers ${ }^{5}$ were asked to work with the Topological Relations Picture Series (TRPS) and the Picture Series for Positional Verbs (PSPV), stimuli designed specifically for the examination of positionals at the Max Planck Institute for Psycholinguistics in Nijmegen (see introduction to this issue for details). These data are supplemented by spontaneous elicitations and some overheard utterances during the fieldwork stay, excerpts of spoken narratives collected during an earlier fieldwork trip to Ardeşen in 1996 (published as Kutscher and Genç 1998), and elicited data from some speakers of Laz living in Germany.

The article is organized as follows. In Section 2 we present the typological characteristics of Laz. In Section 3 we define the components of the BLC in Ardeşen-Laz, and distinguish it from other formally and functionally related constructions. In Section 4 we give an overview of the class of stative verbs and identify its subclass of positional verbs. In Section 5 we discuss each of the positionals listed above in detail. Section 6 presents a summary of our results. 


\section{The main characteristics of Ardeşen-Laz}

In this section, we will give a short overview of those characteristics of Laz that are of interest for the purpose of this article; for further details of the language see Kutscher (2001). Laz is basically a SOV language, exhibiting the categories case and number in nominal expressions and a rich inventory of verbal categories with up to 10 slots in the predicate. Predicates inflect for Plural, Causative, Tense, Aspect, Mood and Actor and Undergoer. They are head marking and exhibit three kinds of paradigms: Active inflection with the logical subject of the predicate being an Actor (1a), inactive inflection with the logical subject of the predicate being an Undergoer (1b) and predicates inflecting for Actor and Undergoer (1c). ${ }^{6}$

(1) a. b-ulur

1A-go:1SG:PRS

'I go.'

b. m-a-çinden

1U-VV-sneeze:>1SG:PRS

'I sneeze.'

c. ce-k-çare

PRV-2U-beat:[1>2]SG:FUT.PFV

'I will beat you!'

Note that information on person and number in Laz predicates is not marked by a single prefix but rather results from the interaction of prefixes and suffixes. The suffixes are portmanteau forms coding person and tense/aspect/mood simultaneously.

In addition to the personal inflection, information on the number and the semantic role of core arguments is also coded in a preroot vowel, the so called version vowel. Laz has three version vowels, each of which expresses the way in which the arguments of a predicate are related (for details, see Kutscher 2001; Kutscher 2007: ch. 6). The version vowel $-i$ indicates that in monovalent predicates the state of affairs is directed towards the actor or, if the predicate is bi- or trivalent that the primary object (in the sense of Dryer 1986, see below) is not affected by the event but rather has the semantic role of beneficiary/recipient or goal. Version vowel $-o$ - codes that the primary object of the expression is affected by the event. The function of version vowel $-a$ - is rather diverse. It occurs with experiencer predicates and derives the potential mood, cf. (2).

(2) çay m-a-šilen

tea 1U-VV-pluck:POT:<1SG:PRS

'I know how to harvest tea' 
Version vowel - $a$ - also expresses topological configurations where surfaces are involved, as the opposition between the predicate with version vowel $-a$ - in (3a) and with version vowel $-i$ - in (3b) illustrates.
a. gza dolv-a-ntxen
road down-VV-plunge:>3SG:PRS
'It plunges down onto the road.'
b. tikina dol-i-ntxen
basket down-VV-plunge:>3SG:PRS
'It plunges down into the basket.'

In contrast to its sister language Georgian (see Boeder 1968), this superessive use of version vowel $-a$ - is rather marginal in Laz and does not seem to be productive any more. None of our consultants used version vowel $-a$ - to express a Figure-Ground configuration related to a surface. Concerning the data on positionals in our sample, we found that Laz also allows for the version vowels $-o$ - and $-i$ - relating to the Ground in a Figure-Ground configuration. The version vowels in these cases can be compared to applicative morphology used in locative alternations (e.g., German laden 'load' vs. beladen 'load with'). A Ground NP that is coreferenced by a version vowel in the predicate is marked as the primary object of the predication, i.e., as a core argument. The presence of a version vowel in these predications depends on the information structure and intention of the speaker. Since this article only deals with the semantics of the positional predicates in Laz, we will not go into detail concerning the function of the version vowel in predicates denoting Figure-Ground configurations.

Laz is a primary object language (in the sense of Dryer 1986), that is, Laz' verbal morphology does not distinguish between direct and indirect objects but the patient/theme of an transitive and the recipient/ beneficiary of a ditransitive predicate are marked the same. The patient/ theme in a ditransitive predicate, on the other hand, is marked differently from the one in a transitive predicate, cf. examples in (4).

$$
\begin{aligned}
& \text { a. (si) (ma) ce-m-çam } \\
& 2 \mathrm{~s} 1 \mathrm{~s} \text { PRV-1U-beat:[2>1]SG:PRS } \\
& \text { 'You beat me.' } \\
& \text { b. (si) (ma) (ham) me-m-çam } \\
& \text { 2s 1s this PRV-1U-give:[2<1]SG:PRS } \\
& \text { 'You give it to me.' }
\end{aligned}
$$

The verbal paradigm is rather uniform in all Laz dialects (apart from phonological differences), but this does not hold for the case inventory. While most Laz dialects have argument marking (absolutive, ergative, 
dative) as well as adjunct marking cases, in the dialect of Ardeşen which is under investigation here - argument NPs are always unmarked for case, as can be seen in (5), where, in contrast to the benefactive bere şeni 'for the child', the theme NP kitabi 'book' is neither inflected for case, nor marked by any other formal means.

(5) bere-şeni kitabi me-m-çi-i?

child-BEN book PRV-1U-give:[2>1]SG:PRS-QU

'Did you give me the book for the child?'

The case system in Ardeşen-Laz is restricted to mark adjunct phrases, such as instrumentals, comitatives, benefactives, goals and sources, as is illustrated in (6), where an example for a goal expression is given.
recě̌ule-şa
eşǩa-ftaten
'place name'-MOT up-go:1A:FUT.PFV:PL
'We will go up to recekule.'

(Kutscher and Genç 1998: gecekule 005)

Temporal and local expressions, however, are always unmarked for case, cf. (7).

(7) a mapxa ndya livadi $\check{\text { p}}$-ťrayudu one sunny day garden 1A-sing:1SG:PAST.PFV

'On a sunny day I sang in the garden.'

Hence, case marking or rather lack thereof cannot be taken as indicator of the argument status of an NP in Ardeşen-Laz (note that in dialectal variants of Laz not under consideration here, the Ground NP would be marked by the dative/locative case, see Holisky 1991). While case marking indicates adjunct phrases in all instances, this does not hold vice versa, as example (7) illustrates. For the temporal expression a mapxa ndya '(on) a sunny day' as well as for the local expression livadi '(in) the garden', neither segmental nor syntactic characteristics can be identified that would argue for their being arguments of the predicate p̌trayudu 'I sang'.

\section{The Basic Locative Construction and related constructions}

\subsection{The Basic Locative Construction}

In Ardeşen-Laz, the Basic Locative Construction (BLC) - that is, the construction being employed in an answer to a 'where is <figure>' question - consists of an optional NP expressing the Figure followed by the Ground NP and a predicate. ${ }^{7}$ The relation between Figure and 
Ground is expressed solely in the predicate by a locational preverb and a positional root. A scheme of the BLC is given in (8) and is illustrated in (9).

(8) ([NP:unmarked $]_{\text {figure }}$ ) $[\mathrm{NP}: \text { unmarked }]_{\text {ground }}\left[\mathrm{V}: \mathrm{PRV}_{\text {TopRel }^{-}}\right.$ Root $_{\text {Positional }}-$ TAMP $\left._{\text {stative }}\right]_{\text {LocRel }}$

(9) a. şişe masa ce-dgun bottle table on-stand:3SG:PRS

'The bottle is (lit.: is standing) on the table.' (PSPV 37)

b. şişe masa ce-zun bottle table on-lie:3SG:PRS 'The bottle is (lit.: is lying) on the table.'

c. şişe ťikina dolo-zun bottle basket inside-lie:3SG:PRS 'The bottle is (lit.: is lying) in the basket.' (PSPV 22)

As the examples (9a) to (9c) show, the verb root and the preverb vary, depending on the relation between Figure and Ground. In (9a) the Figure is placed on a table in an upright position as opposed to (9b), in which the bottle is lying on the table. This variation of the locative orientation of the Figure is expressed by two distinct verb roots, - $d g$ - 'stand' and $-z u$ 'lie'. The preverb in both examples, however, is identical since the location of the Figure being in contact with the upper surface of a table is the same. In (9c) on the other hand, the Figure is placed inside a tubelike entity, a basket, hence the preverb dolo- 'inside' as opposed to ce'on'. In Ardeşen-Laz there are 18 preverbs encoding topological relations of Figure and Ground. Since the detailed semantics of the preverbs do not play a major role in understanding the meaning and use of Laz positional verb roots and the BLC in general, a thorough description of the preverb system is not given in this article (see Kutscher [2003] for further information). We will only give a simplified overview of the preverbs in Ardeşen-Laz in Table 1.

The semantics of the Laz preverbs is distinct from analogous verbal particles and preverbs in German or English. The preverb ce-, for example, translated as 'on' in example (9a) and (9b), is used if the Figure is placed somewhere above the Ground, e.g., on a table or a balcony and if the Figure is of minor extension. $\mathrm{Ce}$ - may also be used in a 'downwards' relation depending on how pronounced the gradient of the angle between Figure and Ground is. For an 'inside' relation in the case of a Figure being placed inside a broad vessel (cf. [29]), such as a pan or a bowl, ce- may also be used as opposed to an 'inside' relation with a tube-like 
Table 1. Set of preverbs in Ardeşen-Laz

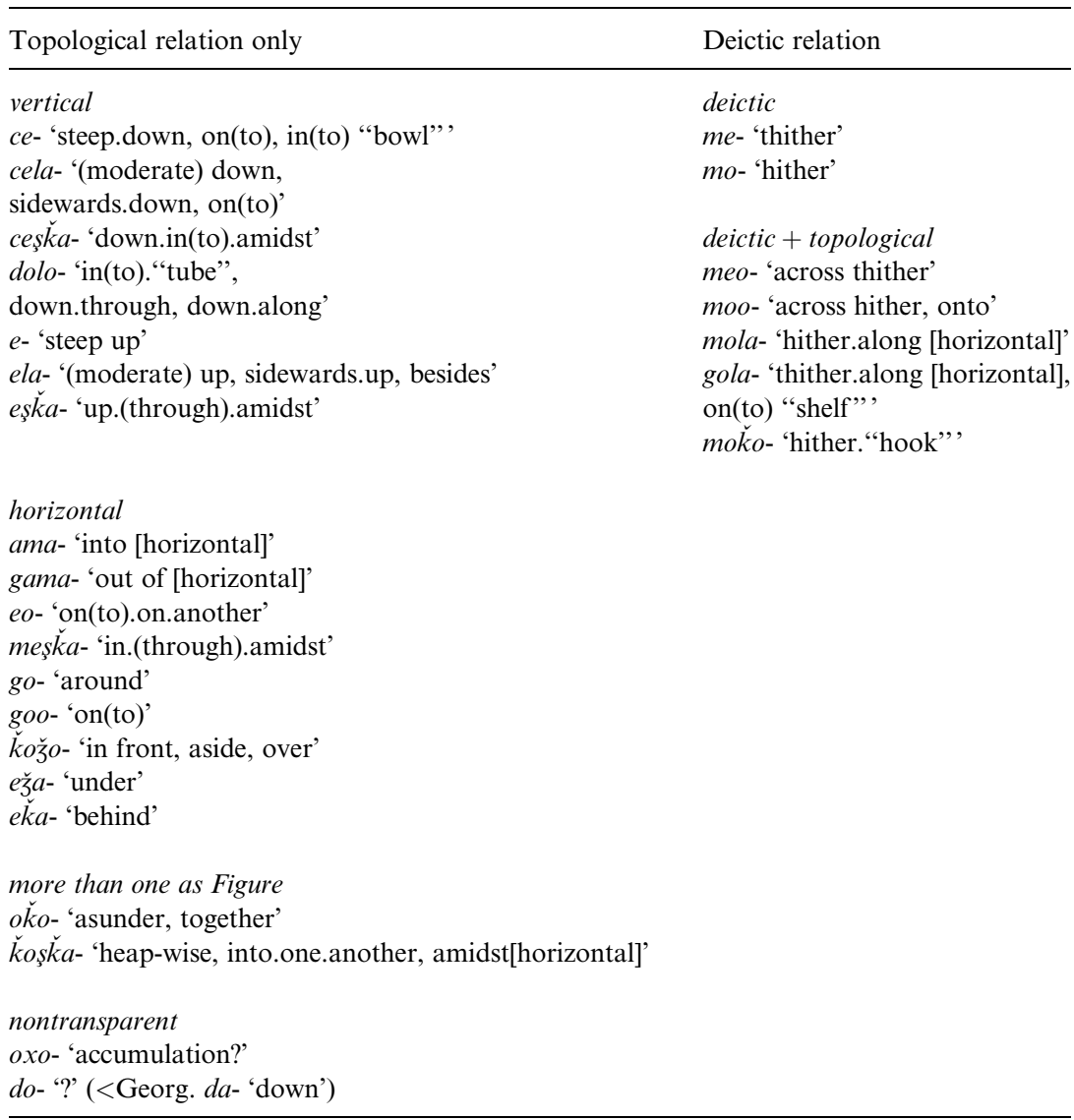

Ground such as a ťikina - a basket carried on the back — where the preverb dolo- is used (cf. [9c]).

Laz has a polypersonal verbal inflection with both predication base ('subject') and objects being represented as bound pronouns on the finite verb (see Kutscher 2001 for details). Hence, the Figure NP in the BLC may be deleted and in spontaneous speech ${ }^{8}$ often is. The Ground NP on the other hand typically is part of the BLC and is the constituent of the construction that bears primary stress. ${ }^{9}$

(10) toçi kfá goo-zun rope stone on-lie:3SG:PRS

'The rope is (lit.: is lying) on the stone.'

(PSPV 3) 
In case of debate or longer descriptions of the topological situation, where not only the Figure but also the Ground has been introduced into discourse, the Ground NP may be deleted. These utterances, however, do not fall under the definition of BLC used in this issue as an utterance given as an answer to a "where" question and hence are excluded in this article.

In the case of predicate focus - another construction type excluded in this article - the Ground NP is normally deleted and the positional verb bears the intonation unit's main stress. Stress, however, is placed in accordance with the stress pattern for Laz verbs in general, i.e., on the preverb or the preroot vowel, not the verb root, cf. (11). Deletion of the positional verb is not possible in any case.

$$
\begin{aligned}
& \text { Q: lobca masa goó-zun-i } \\
& \text { bean(s) table on-lie:3SG:PRS-QU } \\
& \text { goó-byun-i? } \\
& \text { on-be_mass:3SG:PRS-QU }
\end{aligned}
$$

A: goó-byun. on-be_mass:3SG:PRS

Q: 'Are the beans lying or do they 'mass' on the table?' - A:

'They are located as a mass there'

The BLC may be extended by a secondary predicate ${ }^{10}$ to provide more detailed information about the configuration between Figure and Ground than can be coded in the positional predicate alone. The secondary predicate is either a participle as in (25c) and (37c) or an adjective as in (25a). In most cases, secondary predication occurs in noncanonical orientations of a Figure.

\subsection{Related constructions}

3.2.1. The thetic construction. In Ardeşen-Laz there is a construction consisting of the same constituents as the BLC but deviates from that construction in that the Ground NP is sentence-initial and the Figure $\mathrm{NP}$ cannot be omitted. In contrast to the BLC, in this construction the Figure is not the topic of the utterance, and thus this construction cannot be used as an answer to a "where" question. This construction is used to deliver "all new" information and to introduce new topics into the discourse. In our context, speakers used this construction when asked to describe the pictures of the stimuli in TRPS and PSPV instead of being asked "where" questions. An example is given below. 
(12) masa top̆i goo-zun

table ball on-lie:3SG:PRS

'On the table is (lit.: is lying) a ball.'

(PSPV 21)

Note that the word order and the constituents in the thetic construction correspond to the basic sentence construction in Ardeşen-Laz. But as mentioned above, Laz is a language with bound pronominal arguments on the verb. Consequently, "filled sentences" containing predication base and objects all represented by NPs in one intonation unit are rather rare and follow information structure purposes such as mentioned in this section.

3.2.2. The resultative construction. The resultative construction consists of a locative verb participle, formed by -eri 'PTCP', and the copula verb bore 'I am'. In our context, the resultative construction is used only for configurations in which no appropriate positional was found, e.g., in situations of a tight fit (cf. Section 5.9), or as an alternative to a BLC, as in (13).
A: lobca gompin-eri on bean(s) spread-PTCP be:3SG:PRS
where bean(s) be:3SG:PRS
Q: so lobca on?
A: lobca gza gv-o-mpiy
bean(s) road around-VV-be_spread:3SG:PRS

A: 'The beans have been distributed.' - Q: 'Where are the beans?'

— A: 'The beans are (lit.: are spread) on the road.'

(PSPV 11)

3.2.3. The existential construction and negation of BLC. In order to express the existence of entities, Laz speakers use a construction related to the possessive construction already mentioned in Note 7 as the alternative form of "where" questions in Laz. Both the existential and the possession construction may be complemented by a Ground NP. The existential construction can be distinguished from a possession construction in that number suffixes, which give the topic a definite reading, are absent in existential constructions. Thus, whereas the utterance given in (14a) depending on the context has an existential reading, the utterance in (14b) cannot be interpreted as having an existential reading, as it can only be uttered in situations where the glasses already have been introduced into the discourse. 
(14)

a. ho, bardayi (dolabi) m-i-yun

yes glass cupboard 1U-VV-have:<1SG:PRS

'(lit.: Yes, I have glasses [in the cupboard].) There are glasses in my cupboard.'

b. bardaye-pe (dolabi) m-i-yun glass-PL cupboard 1U-VV-have:<1SG:PRS

'(lit.: I have the glasses in the cupboard.) The glasses are in my cupboard.'

The use of the negation proclitic $v a(r)$ on the possessive verb negates the presence of the entity, as is illustrated by the following example.

(15) bardayi va-m-i-yun

glass(es) NEG-1U-VV-have:1s:PRS

'I don't have glasses.'

In order to negate the location of an entity but not its existence, Laz speakers may use either the appropriate positional in combination with the proclitic $v a(r)$, as is illustrated in (14a), or may use the copula on 'it is' instead (cf. [16b]).
$\begin{array}{lll}\text { a. } & \text { kavanozi } & \text { dolabi } \\ \text { preserving_jar } & \text { cupboard }\end{array}$
va-dolo-m-i-dgun
NEG-in-1U-VV-stand:[3<1]SG:PRS
'The preserving jar is (lit.: is standing) not in my cupboard.'

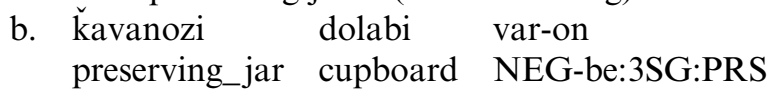
'The preserving jar is not in the cupboard.'

\section{Positionals as a subpart of the stative verb class}

Laz positional verbs are a subgroup of the form class of stative verbs. Stative verbs constitute a form class of their own, since - as opposed to all nonstative verbs - they do not inflect for perfective aspect. They inflect only for the predication base ("subject"), which is either actor or, in case of experiencer verbs, experiencer and hence do not carry a bound object pronoun. Within the class of stative verbs there are verbs with locative as well as nonlocative meanings such as uş̌kun 's/he knows', ncay 's/he sleeps'. Some of those verbs may well be used in a construction similar to the BLC in that the Figure is related to a Ground, as in bere araba ncay 'the child sleeps in the car'. The locative sense of the construction, 
however, is contributed by the Ground NP and only in a secondary sense by the verb itself - one has to sleep in some location and in a certain kind of locational orientation. Consequently, those verbs may not serve as answers in a "where" question and thus are excluded from the analysis.

Other verbs in our data - imçay 's/he/it swims' and ivalen 'it flutters' — were given as answers to "where" questions, but do not belong to the form class of stative verbs and thus are also excluded from the analysis. In addition, we found two stative locative verbs - PRV-svarun 'it is aligned or stacked' and PRV-bun 'it is spilled' - which had to be excluded from the set of positionals because they cannot be used in the BLC, and therefore do not fulfill the defining criterion for a positional.

The stative locative PRV-svarun 'it is aligned or stacked' refers to a quantity of objects being in a row, such as plates on a shelf (cf. [17a]), or layers of rolled-out dough placed one on top of the other when making puff pastry (cf. [17b]).
a. tabaye-pe dolabi
golo-svarun plate-PL cupboard on-be_aligned:3SG:PRS
'The plates lean in a row on the cupboard.'
b. yufka sini ce-svarun puff_pastry tray on-be_aligned:3SG:PRS
'The puff pastry slices lie stacked one on top of the other on the tray.'

As is the case with PRV-mpiy 'it is spread' (cf. Section 5.5), PRV-svarun 'it is aligned or stacked' exhibits a sense of orderly, intentional placement as well. In case of objects overlapping unintentionally, e.g., when rolling out the dough for making the puff pastry, cesvarun 'it is aligned or stacked on' would not be adequate, and cezun 'it lies on' would be preferred. In our data, however, PRV-svarun 'it is aligned or stacked' was not used to describe the configurations given in the stimuli PSPV 42, 47, 53, showing cassavas being placed in a row in various places, although the configuration may be denoted by using PRV-svarun. For these configurations PRV-zun 'it lies' was used instead. It seems that PRV-svarun cannot be classified as a positional in Laz, since it was not used in an answer to a "where" question. The same holds for the locative stative verb PRV-bun 11 'it is spilled'. Formally, these stative locative verbs have the same characteristics as the verbs classified as positionals in this article. Thus, the subclass of positional verbs in Laz can only be established on semantic grounds as those locative stative verbs that denote a configuration of a Figure in relation to its Ground and may serve as answers to a "where" question. 
Since the subject of this article are those positionals denoting the configuration of inanimate Figures, human posture verbs which cannot be used with inanimate Figures such as PRV-mxun 'squat, kneel' have been excluded as well.

Causative counterparts of positionals in Laz are formed with the same roots by changing the conjugation class from a stative to a nonstative paradigm. The causative counterparts do not belong to the stative verb class and consequently inflect for perfective aspect. Both types of verbs can also be distinguished with respect to their imperfective paradigm, as is illustrated by the root -tu- 'cover' in Table 2 below.

Interestingly, there are three exceptions to this rule. 1) The positionals PRV-dgun 'it stands' and PRV-zun 'it lies' do not have causative counterparts formed as shown in Table 2, but the verb PRV-dum 'put' is used as a causative functional equivalent for both. 2) The causative counterpart of the positional PRV-ren denoting the configuration of a liquid as Figure is PRV-bam 'I pour'. In other words, it is formed in analogy to what has been illustrated in Table 2, but with the root which is also found in the stative verb PRV-bun 'it is spilled'. 3) The causative counterpart of PRVnzoy 'it is stuck' is formed with the root -zon-, see also Section 5.9. Note that in contrast to all other verbs discussed in this article, the causative counterpart to PRV-mpiy 'it is spread' contains the causative suffix -in-, hence PRV-bompinam 'I spread sth.'.

We will now have a look at the semantics and use of each of the positional verbs which denote locative configurations of inanimate Figures in Ardeşen-Laz.

Table 2. Laz positionals and their causative counterparts

\begin{tabular}{|c|c|c|c|c|c|}
\hline \multirow[t]{2}{*}{ Root } & \multicolumn{2}{|c|}{ Positional } & \multicolumn{3}{|c|}{ Causative } \\
\hline & PRS & PAST.IPFV & PRS & PAST.IPFV & PAST.PFV \\
\hline $\begin{array}{l}\text {-tu- } \\
\text { 'cover' }\end{array}$ & $\begin{array}{l}\text { PRV-tun } \\
\text { 'it covers' }\end{array}$ & $\begin{array}{l}\text { PRV-turtu } \\
\text { 'it covered' }\end{array}$ & $\begin{array}{l}\text { Prv-tuy } \\
\text { 'he covers it' }\end{array}$ & $\begin{array}{l}\text { PRv-tumť } \\
\text { 'he was covering it' }\end{array}$ & $\begin{array}{l}\text { PRV-tu } \\
\text { 'he covered it' }\end{array}$ \\
\hline
\end{tabular}

\section{The semantics of the Laz positional verbs}

\section{1. $P R V$-dgun 'it stands', $P R V$-ren 'liquid stands'}

Ardeşen-Laz employs two distinct verbs to describe a human Figure in an upright position, dgun 's/he stands' (cf. [18b] and PRV-ren 's/he stands' (cf. [18c]). Both positionals refer to configurations where the Figure 
is supported by its Ground from below. Whereas the $d g u n$ 's/he stands' cannot be prefixed by a locational preverb when referring to a human or animate Figure (cf. [18a] vs. [18b]), PRV-ren 's/he stands' can only be used in combination with a preverb (cf. [18b]). ${ }^{12}$ Therefore, this is the positional that has to be used if the configuration is one that requires the use of a preverb.
a. *Ali masa ce-dgun
Ali table on-stand:3SG:PRS
b. Ali masa-şi cindo dgun
Ali table-GEN surface stand:3SG:PRS
'Ali stands on the table.'
c. Ali masa ce-ren
Ali table on-stand:3SG:PRS
'Ali stands on the table.'

With inanimate Figures, the behavior of this positional is different, as is shown in the next section.

5.1.1. PRV-dgun 'it stands'. When denoting a configuration of an inanimate Figure, $-d g$ - may be combined with any preverb appropriate for describing the locational relation of Figure and Ground as is demonstrated in (19) and (20). Similar to the German positional stehen 'stand', in Ardeşen-Laz PRV-dgun 'it stands' is used for inanimate Figures which exhibit an identifiable part through which the Figure is canonically in contact with its Ground. This "base" may resemble the legs or feet of animates in the case of pieces of furniture such as a table or a stool (cf. [19a]), or the wheels of a vehicle such as a car (cf. [19b]).
a. ̌uli balǩoni cela-dgun
stool balcony on-stand:3SG:PRS
'The stool is (lit.: is standing) on the balcony.'
b. araba oxori eža-dgun
car house behind-stand:3SG:PRS
'The car is (lit.: is standing) behind the house.'

The base may be defined in functional terms as well, as the surface of an object on which it is canonically deposited, as is the case with a television set or a suitcase 'standing upright'.
a. televisioni masa goo-dgun
TV_set table on-stand:3SG:PRS

'The TV set is (lit.: is standing) on the table.' 
b. bavuli oda mola-dgun suitcase room in-stand:3SG:PRS

'The suitcase is standing in the room.'

When the suitcase is placed on its side, e.g., if one wants to put clothes into it, the configuration is denoted as the suitcase 'lying' on the ground, with the use of the positional PRV-zun 'it lies', cf. Section 5.2.

Although exhibiting a clear-cut bottom part on which they are canonically deposited, flexible objects such as carpets - when placed on the ground - can only be describes as 'lying' (see Section 5.2). This shows that PRV-dgun 'it stands' can only refer to rigid Figures which are able to support themselves.

As is illustrated by the following examples, the presence of a clear vertical axis is of secondary importance for the choice of the positional PRVdgun 'it stands'. Entities which exhibit a clear horizontal orientation such as a plate, a tray or a bowl are referred to as 'standing', whereas a book being placed on a shelf in an upright position was nevertheless described as 'lying' by all speakers, (cf. [21b]), with one speaker accepting PRVdgun 'it stands', but stating that it was better to use PRV-zun 'it lies'. ${ }^{13}$
a. tasi masa goo-dgun
bowl table on-stand:3SG:PRS
'The bowl is (lit.: is standing) on the table.'
b. çitabi tereyi gola-zun
book shelf on-lie:3SG:PRS
'The book is (lit.: is lying) on the shelf.'
(TRPS 8)

On the other hand, glasses and cups may well be described as 'lying', even if they are being placed on a canonical Ground, i.e., a table, and in upright position. In contrast to the cup being employed in the stimulus TRPS 1, where the speakers used PRV-dgun 'it stands' (cf. [22a]), the cup which was chosen as the Figure in example (22b) lacks a clear-cut base, that is, the cup is of a cylindrical shape, without a rim or smaller bottom part.
a. masa goo-dgun
table on-stand:3SG:PRS
'It [the cup] is (lit.: is standing) on the table.'
(TRPS 1)
b. masa goo-zun
table on-lie:3SG:PRS
'It [the cup] is (lit.: is lying) on the table.' 
All five speakers who were asked to identify the configuration of such cups or glasses lacking a clear-cut base were insecure about the choice of either PRV-dgun 'it stands' or PRV-zun 'it lies' and accepted both positionals as equally appropriate.

PRV-dgun 'it stands' can also be triggered metonymically as is illustrated in (23), where, strictly speaking, the positional relates to the container wherein the Figure is kept and does not denote the configuration of the Figure itself, as for grainy entities such as salt the appropriate positional would be PRV-byun 'it is located as a mass', cf. Section 5.4.

\section{(23) mcumu masa goo-dgun salt table on-stand:3SG:PRS \\ 'The salt is (lit.: is standing) on the table.'}

For Figures with a noncanonical orientation, speakers vary in their choice of the appropriate positional. In case of the stimulus PSPV 12, a vase-like clay pot standing upside down on a tree stump, three out of four speakers used PRV-zun 'it lies', and only one used PRV-dgun 'it stands'. In case of a bowl standing upside down on a table, both speakers asked used PRV-dgun 'it stands', but accepted PRV-zun 'it lies' as equally appropriate.

The presence of a noncanonical Ground also influences the choice of the positional in that for a plate or a bowl being placed on the floor the two speakers asked accepted or used the positional PRV-zun 'it lies', although for the same Figures, when placed on a table, they used PRVdgun 'it stands' in accordance with the other speakers. This also holds for entities with a vertical axis in an upright position, e.g., a bottle being placed in a basket (PSPV 62) or a pot on a branch in a tree (PSPV 48). For all of these configurations, three out of four speakers used PRV-zun 'it lies' instead of PRV-dgun 'it stands'.

Although 'having a base' is the primary component which triggers the use of PRV-dgun 'it stands', the dimension of verticality is of relevance as an additional criterion. In case of horizontally extended Figures with a base, such as plates or pots, the two speakers asked used PRV-zun 'it lies' when the objects were placed in a cupboard, while with the configuration of a plate on a table they both used PRV-dgun 'it stands'. The same holds for a frying pan: when being stored in a cupboard PRV-zun 'it lies' was used, whereas for denoting the configuration of a frying pan being placed on a stove PRV-dgun 'it stands' was used. Those findings cannot be confirmed for Figures extending vertically, such as a tea pot or a preserving jar. For these entities, the same speakers used PRV-dgun 'it stands' even when the objects were placed in a cupboard. 
5.1.2. $\quad P R V$-ren 'liquid stands'. PRV-ren 'stand' may be used for Figures denoting humans as is illustrated in (18c) or trees (cf. [24a]) as well as for liquids (cf. [24b]). For these entities, PRV-dgun 'it stands' cannot be used. Since the object of this article is the use and semantics of positional verbs that denote configurations of inanimate Figures, we will gloss PRV-ren as 'liquid stands' in this article and will not further investigate the use of this positional with Figures denoting humans and other animates, including trees.

$$
\begin{aligned}
& \text { a. mca çilise el-u-ren } \\
& \text { tree church beside-VV'14-stand:3SG:PRS } \\
& \text { 'The tree is (lit.: is standing) beside the church.' } \\
& \text { (TRPS 49) } \\
& \text { b. tasi dolo-ren } \\
& \text { bowl in-stand:3SG:PRS } \\
& \text { 'It is (lit.: is standing) in the bowl.' } \\
& \text { (TRPS 32, modified question: 'Where is the water?') }
\end{aligned}
$$

When referring to liquids, the use of PRV-ren 'liquid stands' is appropriate regardless of the Ground to which the liquid is related, that is PRVren 'liquid stands' is used to denote the configuration of a liquid in a container as well as on the Ground. It refers only to the location of the liquid and unlike the stative verb PRV-bun 'it is spilled' does not contain a resultative component and hence can be used in an answer to a "where" question.

\section{2. $P R V$-zun 'it lies', no-zun 'it leans'}

Similar to PRV-dgun 'it stands', in Ardeşen-Laz the positional PRV-zun 'it lies' is not used for human beings and other animates, although etymologically it denotes a human posture (cf. Fähnrich and Sardschweladse 1995: 475). In contrast to dgun 'it stands', the verb zun 'it lies' without preverb is not used to denote a human posture. In order to refer to a configuration of a person being placed horizontally, the locative verb PRV-ncar that also translates as 'to sleep' has to be used.

With inanimates, however, PRV-zun 'it lies' is used frequently in our data. It denotes configurations of Figures supported from below when the Figure lacks a base, as was illustrated with some of the examples in Section 5.1.1 above, and when its most salient axis is aligned horizontally (cf. [25a]) or lacks a salient dimension, i.e., when it is round or otherwise symmetrically or near-symmetrically extended, cf. (25b). 
a. biga masa ǎ̌iri goo-zun

stick table diagonally on-lie:3SG:PRS

'The stick is (lit.: is lying) on the table diagonally.'

(PSPV 6)

b. tope-pe masa eo-zunan

ball-PL table on-lie:3PL:PRS

'The balls are (lit.: are lying) on the table.' (PSPV 8)

c. masa-şi cindo oǩoǩoť-eri eo-zun table-GEN surface fold_half-PTCP on-lie:3SG:PRS 'It is lying on the top of the table folded in half.' (PSPV 14)

The positional PRV-zun 'it lies' may be used with rigid entities (cf. [25a]) or flexible ones such as a rope or a piece of cloth (cf. [25c]), but it may not be used for Figures which are conceptualized as masses, in which case PRV-b zun has to be chosen, see Section 5.4. In the case of several individual entities such as a group of balls or bottles being on a table, the use of PRV-zun 'it lies' overlaps with the use of PRV-mpiy 'it is spread', see Section 5.5 for details.

PRV-zun 'it lies' is in complementary distribution with PRV-dgun 'it stands' for Figures conceptualized as having a base but not being placed on it, such as the bottles in the stimuli PSPV 22 (bottle in a basket), 26 (bottle balancing on a stone), 52 (bottles lying on a table), 60 (several bottles jammed into a basket), and 67 (a bottle put upside down into a basket) or the pot in PSPV 40 (a clay pot lying beneath a tree stump). For all these configurations all speakers preferred to use PRV-zun 'it lies' (see also Section 5.1.1).

With configurations of a Figure being in contact with two surfaces, with an empty space between the two zones of contact, the positional no-zun 'it leans' is used. As a result of this semantic requirement, only rigid entities which can bear their own weight without being deformed can be described as 'leaning'. The positional no-zun 'it leans' consists of the deictic preverb me- 'hither'15 and the same root $-z u$ - 'lie' as in PRV-zun 'it lies' but has undergone semantic specialization.

As mentioned above, the use of no-zun 'it leans' requires two supporting surfaces, that is, this verb cannot be used where a Figure is in contact with a single surface only, even when it is supported in two different places. Thus the configuration of an opened umbrella touching the floor with its handle and with one of its spokes can only be described by the positional PRV-zun 'it lies'. 
Interestingly, the semantics of no-zun 'it leans' seems to include a sense of a Figure being outside of its supporting object. While all speakers agreed in using no-zun 'it leans' for configurations such as a stick leaning on a basket (PSPV 13) when the Figure is outside of the container, for a stick being inside the basket leaning on the rim, the speakers preferred PRV-zun 'it lies', and one speaker explicitly denied the possibility of using no-zun 'it leans' when asked.

\section{3. $P R V$-xen 'it sits'}

The verb PRV-xen 'it sits' is a positional basically describing the posture of a human being seated. It may also be used with animals. Apart from relating to the actual posture of an animate Figure, it may also be extended metaphorically. The utterance given in (26a) describes a person up on a roof. It implies that he is working and does not describe the actual posture or position of the person, as opposed to example sentence (26b), where the positional relates only to the actual posture of the person.
a. ǩçi otfa ce-xen
man roof on-sit:3SG:PRS
'The man is busy on the roof.'
(TRPS 34)
$\begin{array}{lll}\text { b. k̆oçi otfa ce-ren } \\ \text { man } & \text { roof on-stand:3SG:PRS }\end{array}$
'The man is (lit.: is standing) on the roof.'
(TRPS 34)

PRV-xen is also used to express the place of residence. ${ }^{16}$ For someone at home who is not busy, the positional PRV-xen 'it sits' is used regardless of his/her actual posture.

PRV-xen 'it sits' may also relate to a configuration with an inanimate Figure being supported from below, such as writing on a T-shirt (TRPS 68), or a picture on a stamp, cf. (27). For this configuration all speakers used PRV-xen 'it sits'.

oxorza-şi rezimi puli ce-xen
woman-GEN picture stamp on-sit:3SG:PRS
'The picture of a woman is (lit.: is sitting) on the stamp.'
(TRPS 28)

In these cases, the positional denotes a configuration of an entity being placed permanently. The use of PRV-xen 'it sits' for inanimate Figures may be explained as the result of a metaphorical extension of the human 
posture verb xen 'sit' to a reading of the posture verb as expression of a human being placed somewhere over a longer period (being busy or reside somewhere) to a reading expressing permanent location only.

\subsection{PRV-byun 'it (mass) is located'}

Unlike in other dialects of Laz, ${ }^{17}$ in the variety of Ardeşen the verb PRVbyun 'it (mass) is located' denotes the configuration of a Figure which is conceptualized as a mass of pieces, such as beans, as is illustrated in the following example.

(28) lobca avla elv-o-byun

beans yard along-VV-be_mass:3SG:PRS

'The beans are spread in the yard.'

(PSPV 11)

For PRV-byun 'it (mass) is located', the meaning component of the Figure consisting of a collection of several solid pieces is essential. It may not be used for liquids or sticky substances such as cooked bulgur. In this case, the bulgur is conceptualized as a single piece and its Figure-Ground configuration has to be denoted as 'lying'.

(29) bulguri tasi ce-zun

bulgur bowl in-lie:3SG:PRS

'The (cooked) bulgur is (lit.: is lying) in the bowl.'

If the verb cezun 'it lies on' is replaced by cebrun 'it (mass) is located on', the only interpretation possible will be a bowl of uncooked grains of bulgur.

PRV-byun 'it (mass) is located' may refer even to very finely grained substances in which the objects can hardly be individuated, such as finely grained corn (cf. [30a]) as well as a collection of objects which in other situations may be individualized, ${ }^{18}$ such as books (cf. [30b]) or even people (cf. [30c]).

(30) a. mçveri bardayi dolv-o-byun

flour glass inside-VV-be_mass:3SG:PRS

'The flour is in the glass.'

b. çitabi masa goo-byun

book table on-be_mass:3SG:PRS

'The books are spread all over the table.'

c. k̆amioni ce-b-o-byurt

truck on-1A-VV-be_mass:[1<3]PL:PRS

'We are stuffed on the truck.' 
In (30a), the flour is stored in a container. When the flour is on a surface, such as a table, PRV-byun 'it (mass) is located' may also be used. In this case the flour would be placed on this surface unintentionally, since the positional has a meaning component of several pieces being located in an unorderly and unintentional way. It is this component that definitely leads to the choice of PRV-byun 'it (mass) is located' in (30b) and (30c). In (30b), the books are all over the table, not being placed neatly, or in heaps. As is illustrated by example (30c), PRV-byun 'it (mass) is located' may also be used metaphorically with Figure NPs denoting human beings. In the situation described in (30c), a group of people are on the loading space of a truck, returning home after work in a tea plantation. As is demonstrated by these examples, the choice of PRV-byun 'it (mass) is located' depends on the speaker's conceptualization of the Figure referent or rather on the speaker's pragmatic intention. Therefore, the use of PRV-byun 'it (mass) is located' may overlap with the use of other positionals, such as the positional PRV-mpiy 'it is spread' (cf. Section 5.5), or e.g., the positionals that would be adequate for the same configuration with a single Figure, thus individualizing the single components of the Figure in question. This is the case for objects which can appear as a single item in everyday life, such as balls or bottles. In these cases, most of the speakers did not use PRV-byun 'it (mass) is located', whereas for Figures normally appearing in a large quantity, such as beans, all speakers used either PRV-byun 'it (mass) is located' or PRV-mpiy 'it is spread'. (For a single bean lying on a table, however, PRV-zun 'it lies' has to be used).

As will be shown in Section 5.6, in case of semiliquid substances such as jam, Laz employs the positional PRV-sun 'it is smeared', and the positional PRV-byun 'it (mass) is located' cannot be used.

\section{5. $P R V$-mpiy 'it is spread'}

The positional verb PRV-mpiy 'it is spread' is used for a Figure which expands on a surface. The Figure may be in one piece, such as a piece of cloth (cf. [31a]) or it may consist of several pieces, such as books (cf. [31b]), but it cannot be used for semiliquid substances (cf. Section 5.6).

(31) a. (mçita şeyi) masa goo-mpiy red cloth table on-be_spread:3SG:PRS 'It (the red piece of cloth) is spread on the table.' (PSPV 30) 


\section{b. (çitabe-pe) masa goo-mpiy book-PL table on-be_spread:3SG:PRS 'The books are distributed on the table.'}

As was shown in Section 5.4 above, in Ardeşen-Laz there is a positional verb denoting configurations of masses as Figures. For the configuration of a mass of beans lying on a table, however, one speaker used PRV-mpiy 'it is spread' instead of PRV-byun 'it (mass) is located'. Further elicitations and folk definitions lead to the conclusion that PRV-mpiy it is spread' has a sense of a Figure being spread in an orderly way, for instance hazelnuts or beans being spread evenly on a roof in order to be dried in the sun, or flour on a table to roll out dough, while PRV-byun 'it (mass) is located' has a sense of disorderliness. Intersections between PRV-mpiy 'it is spread' with PRV-tun 'it covers' (see Section 5.7) are found for configurations such as in PSPV 30 (a tablecloth covering a table) since the tablecloth covers the table top completely. In PSPV 14 (a tablecloth lying in the middle of a table) goozun 'it is lying on it' is preferred to goompiy 'it is spread on it', since the cloth is not completely unfolded, i.e., one cannot speak of it as being spread properly.

PRV-mpiy 'it is spread' may also be used for a piece of cloth (cf. [32a]) or several pieces of rope being placed in a tree (cf. [32b]), although only one speaker out of the four chose this positional.
a. mçita şeyi ayaci ndali red cloth tree branch gv-o-mpiy around-VV-be_spread:3SG:PRS 'The red cloth is spread over the branches of the tree.' (PSPV 59)
b. ǩť-eri ayaci ndali gv-o-mpiy fold-PTCP tree branch around-VV-be_spread:3SG:PRS 'It is spread over the branch of the tree, folded.' (PSPV 57)

For describing the configuration in (32a), PRV-zun 'it lies' is preferred by three speakers and for the situation in (32b) PRV-byun 'it (mass) is located' and PRV-bun 'it hangs' are the alternatives.

\section{6. $P R V$-sun 'it is smeared'}

The positional PRV-sun 'it is smeared' is used in configurations of a soft, semiliquid substance being spread on a surface, such as jam, butter or honey, as is illustrated in (33). 
(33) xami n-u-sun

knife hither-VV-be_smeared:3SG:PRS

'It is smeared on the knife.'

(TRPS 12)

It cannot be used for Figures consisting of solid objects such as a quantity of hazelnuts or the like, for which PRV-byun 'it (mass) is located' is to be used, see Section 5.4. The substance itself may be described as sticky, as in (34).

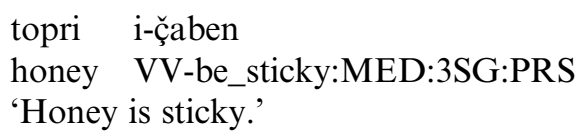

But in contrast to, say, German kleben 'to stick', the stickiness of the substance is not sufficient to license the use of the positional PRV-çabun 'it sticks to'; see Section 5.10 for details.

PRV-sun 'it is smeared' may also be used for liquid substances such as oil or water, e.g., if spread on a loaf of dough that is to be baked. But the use of PRV-sun 'it is smeared' for liquid objects is restricted to those configurations in which the location of the liquid is the result of an intended act. Otherwise, the nonpositional stative verb PRV-bun 'it is spilled' ${ }^{19}$ or the positional verb PRV-ren 'liquid stands' (see Section 5.1.2) is used.

\section{7. $P R V$-tun 'it covers'}

In contrast to PRV-mpiy 'it is spread', the positional verb PRV-tun 'it covers' denotes a configuration of a Figure covering its Ground completely, such as a lid on a pot (35a), or a piece of cloth covering a table top (35b), as is illustrated below.

$$
\begin{aligned}
& \text { a. tencere goo-tun } \\
& \text { pot on-cover:3SG:PRS } \\
& \text { 'It is on the pot in a covering relation.' } \\
& \text { b. masa mo-tun } \\
& \text { table towards-cover:3SG:PRS } \\
& \text { 'It covers the table.' } \\
& \text { (PSPV 30) }
\end{aligned}
$$

If the Figure does not cover the Ground completely, e.g., in stimulus PSPV 4 (a tablecloth folded several times in the middle of a table) and 14 (the same configuration with the cloth folded only once), where the cloth is folded, or with a carpet being rolled up, PRV-zun 'it lies' is used. 
PRV-tun 'it covers' may also be used for objects with a clear three dimensional extension such as a hat on a head as in (36).

(36) ̌̌oçi c-o-tun

man on-VV-cover:3SG:PRS

'It (the hat) covers the (head of) the man.'

(TRPS 5)

Out of four speakers, three chose only this positional and one speaker accepted cezun 'it is lying on' as an alternative. Interestingly, all four speakers chose $\check{k}$ oç $i$ 'man' to denote the Figure in TRPS 5 instead of $t i$ 'head'. It seems to be the case that the use of cotun 'it covers on' here is a semantic extension of the configuration given in (35a), thus conceptualizing a man with a hat as being the same as a pot having a lid.

\section{8. $P R V$-bun 'it hangs'}

The positional PRV-bun 'it hangs' denotes the relation between a Figure and its Ground where a Figure is only attached to the Ground at one point, typically the highest part of the Figure, and lacks support from below. As a result, the configuration of the Figure is determined by gravity, i.e., from the point of attachment downwards. Examples of inanimate Figures in our data comprise flexible entities such as ropes, pieces of cloth, or clothing (cf. [37a]) or solid objects such as a picture on a wall (cf. [37b]) or a stick being attached to the branch of a tree, cf. (37c).

(37) a. patto aski cela-bun jacket hook down-hang:3SG:PRS

'The jacket is attached (lit.: hangs down from) to the hook.' (TRPS 9)

b. resimi ǩoda cela-bun picture wall down-hang:3SG:PRS

'The picture is hanging on the wall.'

(TRPS 44)

c. ayaci-şi ndali eǩkap-eri c-o-bun tree-GEN branch hook-PTCP down-VV-hang:3SG:PRS 'It is hanging from the branch of the tree as if hooked.' (PSPV 55)

PRV-bun 'it hangs' may also be used for animate Figures, e.g., a person in a tree, hands on a branch and dangling freely, or in figurative use for a small child clinging to its mother's skirt, as in (38). 


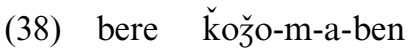

child in_front-1U-VV-hang:>1SG:PRS

'The child clings to my skirt.'

For (parts of) plants, PRV-bun 'it hangs' may be used as well (cf. (39)), although Laz has a verb restricted to plants (and parts of plants such as fruits or leaves) - PRV-nçay 'it grows' - which may be used in an answer to a where question but was excluded from this article since it does not belong to the form class of stative verbs.

(39) oşǩuri ndali ǩoža-bun

apple branch in_front-hang:3SG:PRS

'The apple hangs on the branch.'

(TRPS 27)

The use of PRV-bun 'it hangs' is not restricted to Figures being attached only to one point. In case of clothes being attached to a rope for drying (cf. [40a]), PRV-bun 'it hangs' is the only positional used in our data. In case of noncanonical configurations such as a piece of cloth lying on a table and dangling halfway down to the ground (cf. [40b]) PRV-bun it hangs' may also be used, thus emphasizing the downward orientation of the Figure.

$$
\begin{aligned}
& \text { a. porça toçi c-o-bun } \\
& \text { dress(es) rope down-VV-hang:3SG:PRS } \\
& \text { 'The dresses hang down from the rope.' } \\
& \text { (TRPS 37) } \\
& \text { b. masa-şi çenari cel-o-bun } \\
& \text { table-GEN rim down-VV-hang:3SG:PRS } \\
& \text { 'It is hanging down from the rim of the table.' } \\
& \text { (PSPV 49) }
\end{aligned}
$$

The meaning of PRV-bun 'it hangs' does not include a component of dangling or potential dangling, since it also applies to objects being attached to walls, such as telephones (cf. [41a]). Even for denoting the configuration of a rope or piece of cloth being placed on a stone with part of it lying on the ground (cf. [41b]), two out of four speakers chose the positional PRV-bun.

(41) a. telefoni ̌̌oda n-o-bun, phone wall hither-VV-hang:3SG:PRS cela-bun down-hang:3SG:PRS

'The phone hangs on the wall.'

(TRPS 25) 


\author{
b. kfa-şi cindo n-o-bun, \\ stone-GEN surface hither-VV-hang:3SG:PRS \\ eo-bun \\ on-hang:3SG:PRS \\ 'It hangs down from the top of the stone.'
}

(PSPV 32)

For the configuration of a piece of cloth being attached to the side of a tree stump (PSPV 68) - a configuration comparable to the one in (41b) - all speakers used PRV-bun 'it hangs', although other positionals were also used and all speakers showed some insecurity in describing the quite noncanonical configuration. In all these cases, the component of 'lacking support from below' seems to be the most prominent one, as not only things attached to walls are only supported from the side, but in configurations such as given in (41b), the Figure is touching the Ground but cannot be seen as being supported by it because of its lack of rigidity.

The meaning component of 'lacking support from below', however, does not suffice for the use of PRV-bun 'it hangs' in other configurations, as may be illustrated by the data referring to the stimulus PSPV 44 (a ball hanging between two branches). None of the speakers in our data used or accepted PRV-bun 'it hangs' as adequate in denoting the configuration of a ball being placed between two branches in a tree. Instead, all speakers chose PRV-zun 'it lies' as the appropriate positional. Further elicitation showed that the more or less vertical orientation of the Figure downwards from the point of attachment is essential for the use of PRV-bun 'it hangs'. Neither flexible objects such as ropes nor solid ones such as a stick may be described as 'hanging' in case of configurations such as given in stimuli PSPV 57 (a rope placed horizontally on three branches) or 66 (a stick placed the same way), where the Figure is attached only to some points, such as some branches in a tree, but being oriented horizontally.

\title{
5.9. $P R V$-nzoy 'it is stuck', go-ntun 'it is dipped'
}

The positional verb PRV-nzoy 'it is stuck' prototypically denotes a configuration of a Figure fit tightly into a Ground, such as a cork in a bottle (cf. [42a]) or a stick in the ground (cf. [42b]).

(42) a. mantari şişe dolv-o-nzoy cork bottle inside-VV-be_stuck:3SG:PRS

'The cork is stuck in the bottle.'

(TRPS 62) 
b. cur biga lěta c-o-nzoy two stick earth down-VV-be_stuck:3SG:PRS 'The two sticks are stuck into the ground.' (PSPV 9)

In case of configurations where something is put into a Ground with the Ground not holding tight to the Figure, PRV-nzoy 'it is stuck' may overlap with the use of PRV-zun 'it lies'. For the configuration of flowers put into a vase, one of two speakers used PRV-nzoy 'it is stuck', whereas the other one explicitly refused it, using dolozun 'it lies in it' instead.

According to a folk definition given by one speaker, with the use of PRV-nzoy 'it is stuck', a meaning component of nonpermanency and easy removability is included. If a Figure is jammed and cannot be removed easily, such as a key in the wrong keyhole or a person who tried to escape through a window, but is too big to get through the opening, the active verb PRV-kaçam 'grasp' - where the Ground is represented as the agent - has to be used to describe the situation (cf. [43]). In order to emphasize the static nature of the situation, the result construction mentioned in Section 3.2.2 may be used.

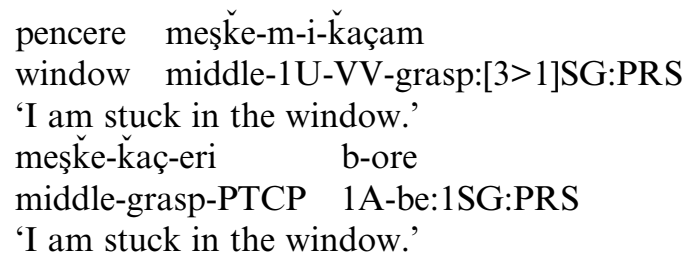

In configurations with a liquid or a powder as Ground, such as a spoon in a coffee can or in a cup of tea, the positional go-ntun 'it is dipped' is used.
(44) ̌̌uzi ̌̌ahve g-u-nťun spoon coffee around-VV-be_dipped:3SG:PRS
'The spoon is dipped into the coffee (powder).'

Note that the use of the preverb go- 'around' - denoting the containment relation as a Ground being 'around' a Figure - is lexicalized with this positional, no other preverbs can be combined with the root -ntun-. In order to use go-ntun 'it is dipped', the part of the Figure that is conceptualized as its relevant or main part has to be 'dipped' into the Ground. Hence the two speakers queried refused to denote a configuration of flowers in a vase (where the relevant part, the bloom, is outside the vase) by using go-ntun 'it is dipped'. The use of go-ntun 'it is dipped' also implies that the Figure can be removed from the Ground without any effort. Thus, a configuration of a stick put into concrete cannot be denoted by 
go-nťun 'it is dipped', since the stick cannot be removed from the concrete. To denote these configurations, one has to use PRV-nzoy 'it is stuck' or a construction similar to the one given in example (43) containing the active verb PRV-̌̌kaçam 'grasp'.

In configurations with liquid Grounds, such as a spoon in a cup of tea, go-ntun 'it is dipped' may overlap with dolozun 'it lies in it', depending on the speakers pragmatic intentions. The choice of go-ntun 'it is dipped' highlights the liquid as the Ground, whereas the use of dolozun 'it lies in it' places the focus on the vessel. If the Figure is covered by the Ground completely, only dolozun 'it lies in it' can be used.

\subsection{0. $P R V$-çabun 'it sticks to'}

The positional PRV-çabun 'it sticks to' prototypically denotes a configuration of a Figure being attached to a Ground by means of a sticky substance. Note that the root $-\check{c} a b$ - is also found in the Laz noun $\breve{c} a b u$ meaning 'glue'. According to Fähnrich and Sardschweladse (1995: 520), the root can be found in all South-Caucasian languages except Svan, meaning 'stick to, glue'. In our data, the positional is used to denote configurations like a stamp on a letter, a Band-Aid on a leg, or chewing gum stuck under a table top as is illustrated by the following example.

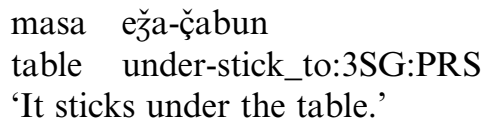

masa ě̌a-çabun

table under-stick_to:3SG:PRS

'It sticks under the table.'

(TRPS 53)

In the above-mentioned configurations, all speakers agreed in using PRVçabun 'it sticks to'. It may also be used with a sense of metaphorical extensions, e.g., in configurations where the Figure is not attached by a sticky substance but by magnetism.

With the stimulus given in TRPS 12 showing the configuration of jam on a knife, however, all speakers in our data only used PRV-sun 'it is smeared', as was illustrated in Section 5.6. This even holds in configurations where glue is the Figure, as in (46).

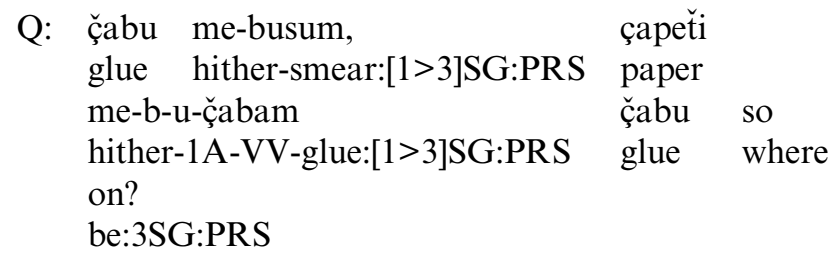


A: ç̧abu çapeťi n-u-sun glue paper hither-VV-be_smeared:3SG:PRS

Q: çabu çapeťi me-çabun glue paper hither-stick_to:3SG:PRS i-ťkvaten-i? VV-say:MED:3PL:PRS-QU

A: var no

Q: 'I put glue on it and I glue pieces of paper together. Where is the glue?' - A: 'The glue is smeared on the paper.' Q: 'Does one say the glue sticks to the paper?' - A: 'No.'

When asked for a definition of PRV-çabun 'it sticks to', one speaker offered the explanation that only solid objects can serve as a Figure in a configuration that can be denoted with PRV-çabun 'it sticks to', while as shown in Section 5.6, PRV-sun 'it is smeared' can only be used for homogenous mass-like substances.

\subsection{1. $P R V$-̌̌orun 'it is bound'}

The positional PRV-̌̌rorun 'it is bound' is restricted to flexible rope-like Figures which are attached to their Ground by a knot or by being wound around it. In our sample, only two preverbs are found in combination with the root - $\breve{k}$ or- 'bind', the deictic preverb me- 'hither and the locational preverb go- 'around'. In configurations as given in TRPS 20, where a balloon is tied to a stick by a piece of rope, the preverb me- 'hither' was used by all speakers. When prefixed with the preverb go- 'around', the positional is used to denote the circumlocation of a Figure in relation to its Ground, such as ropes being wound around a tree stump or a stone, as is illustrated in the following example.

(47) toç̌i kfa gv-o-̌̌orun

rope stone around-VV-be_bound:3SG:PRS

'The rope is wound around the stone.'

(PSPV 15)

The positional go-̌̌rom 'it is wound around' is restricted to configurations in which the Figure is wound completely around its Ground. No speaker accepted PRV-ǩorun 'it is bound' for configurations as are given in the stimuli PSPV 3 (rope lying across a round stone), 16 (big tablecloth lying across a basket and almost covering it), 32 (a piece of cloth lying 
across a round stone), 33 (a rope folded several times and lying across a branch in a tree), 41 (a rope folded in half and lying across a corner of a table), 45 (a rope lying across a tree stump) or 63 (a long rope folded several times and lying across a smaller basket) in which ropes or pieces of cloth partly encircle various Grounds.

Go-korun 'it is wound around' may also be metaphorically extended and used for human beings, e.g., a child embracing his/her mother, as in (48).

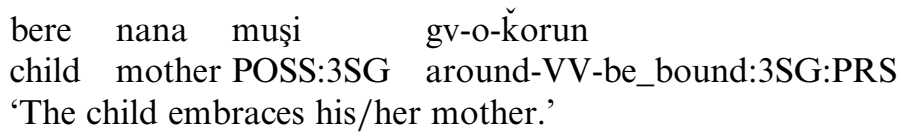

The use of the positional go-̌̌orun 'it is wound around' may overlap with PRV-zun 'it lies' as can be illustrated with the stimulus TRPS 4, which shows a ribbon wound around a candle. One speaker gave a folketymological interpretation of PRV- $\breve{k}$ orun 'it is bound' as being used more readily when emphasizing the rather prominent bow, while preferring cezun 'it lies on' when concentrating on the ribbon being located on the candle.

\subsection{2. $P R V$-gzun 'fire burns'}

The positional PRV-gzun 'fire burns' refers to a topological configuration where a fire is the Figure, as is shown in the following example.

$$
\begin{aligned}
& \text { daçxuri tava ě̌-u-gzun } \\
& \text { fire big_pan under-VV-burn:3SG:PRS } \\
& \text { 'The fire is burning under the big pan.' }
\end{aligned}
$$

In contrast to PRV-gzun 'fire burns', the stative verb içven 'it burns' relates to entities other than the fire itself, such as a dress that is burning (cf. [50]). For this situation, the use of PRV-gzun 'fire burns' is not appropriate.

$\begin{array}{llll}\text { porça sǩani i-ç̌ven } & / & \text { *gzun } \\ \text { dress POSS:2SG VV-burn:MED:3SG:PRS } & \text { burn:3SG:PRS } \\ \text { 'Your dress burns.' } & \end{array}$

The causative counterpart of this positional is PRV-gzam, meaning 'set fire to'. The nonstative verb containing the root $-\check{c} v$ - 'burn' on the other hand cannot be used with this implication, but can only denote 
an event of something burning or a person burning, frying or baking something.

\section{Conclusion}

In this article we tried to illustrate the semantics and use of positional verbs in Laz, denoting configurations with inanimate Figures. Following the definition given in the introduction of this issue, positionals were understood as verbs given in a Basic Locative Construction (BLC). For Laz, we identified the BLC as consisting of a stative locative verb obligatorily occurring with a preverb and two NPs unmarked for case denoting the Figure and the Ground.

As the discussion in Section 5 showed, Laz should be regarded as a multiverb language in the typology proposed by Ameka and Levinson in the introduction to this issue. As predicted in the typology for a multiverb language, positionals in Laz are used to denote the precise spatial disposition of a Figure in relation to a Ground (as it is conceived by the speaker), rather than having sortal classifying functions (a characteristic which Ameka and Levinson predict for postural verb languages in their typology).

The following flowchart summarizes the semantics and the condition of use of the 14 positional verbs discussed in Section 5.

As is illustrated by the flowchart in Figure 1, Laz positionals can be divided into several subgroups according to the type of configuration they denote. Three verbs are used to describe a configuration of containment, i.e., a configuration where the Figure is conceptualized as being partially or fully inside a Ground. Of these three verbs, the verb go-ntun 'be dipped' has the additional component 'Ground is liquid', whereas the verb PRV-nzoy 'be stuck' is used if the containment of the Figure is one of tight fit. The verb PRV-zun 'lie' is used to denote configurations of containment that are neither characterized by tight fit nor by a liquid Ground. In this respect the verb PRV-zun 'lie' can be regarded as a residual verb.

The second comparatively large group of six positionals all share the component of 'support'. Five of them require a support from below, while PRV-bun 'hang' is used to denote configurations in which the Figure is supported from above. For all but one (PRV-xen 'sit') of the five positionals that are used to denote configurations with a Ground that supports the Figure from below, the use of the verb is conditioned by a certain characteristic of the Figure. The use of PRV-gzun 'burn' is restricted to fire as a Figure; the verbs PRV-byun 'be located as mass', 


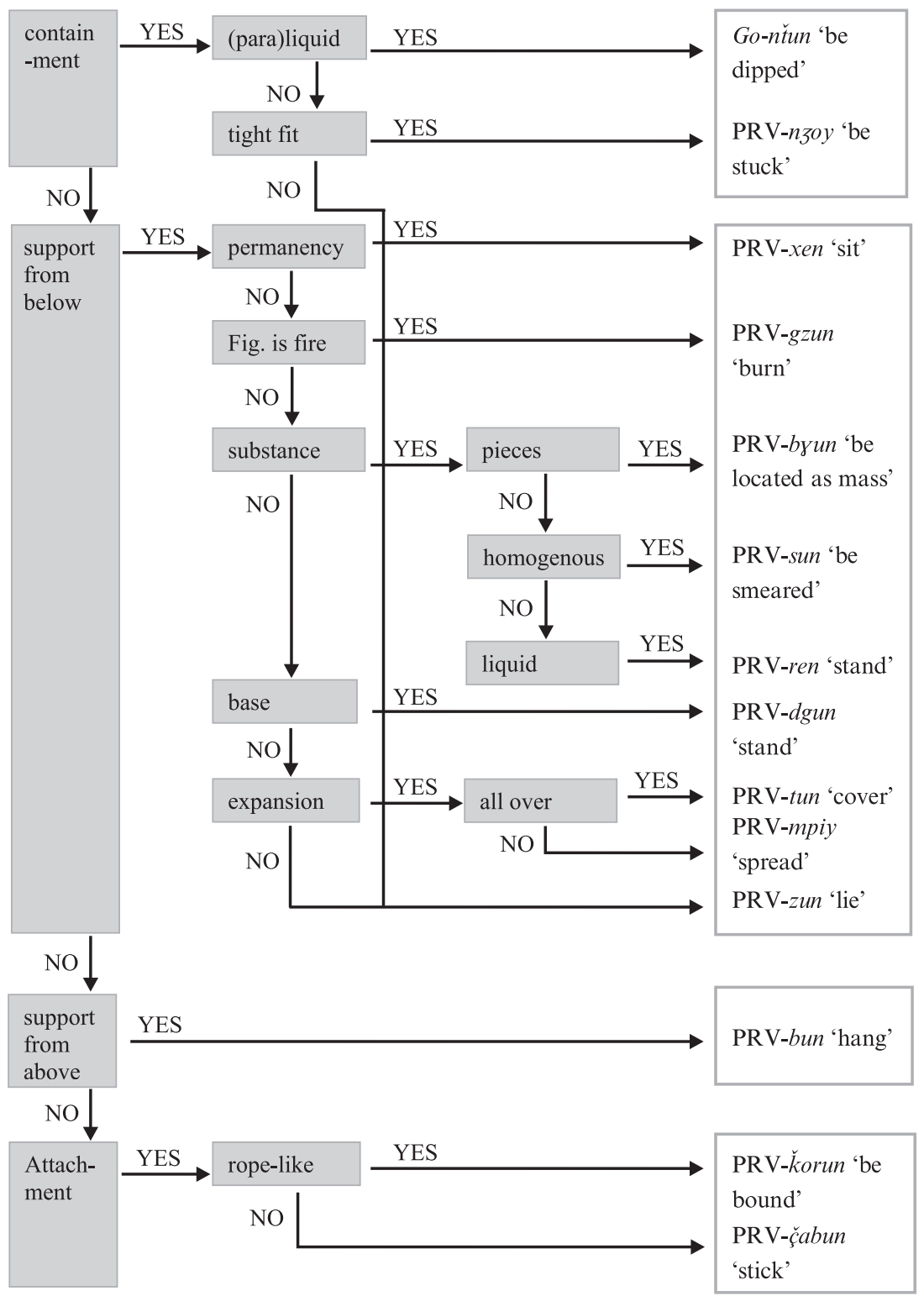

Figure 1. Meaning components of positional verbs in Laz (Ardeşen dialect) 
PRV-sun 'be smeared', and PRV-ren 'stand' are restricted to Figures that are conceptualized as substances; the verbs PRV-tun 'cover', PRV-mpiy 'spread', and PRV-dgun 'stand' are mainly used with Figures that are conceptualized as entities. For the use of the verb PRV-xen 'sit' the contact between Figure and Ground is conceptualized as one of relative permanency. The positional verb PRV-zun 'lie' one the one hand is in direct opposition to the positional PRV-dgun 'stand' with respect to Figures that are conceptualized as having a base, where PRV-dgun 'stand' is used in contrast to Figures with no base, for which PRV-zun 'lie' is used. The positional PRV-zun 'lie' serves as a residual verb for configurations conceptualized as a Figure being supported by a Ground from below if none of the other components listed apply. The positional PRV-zun 'it lies' shows also a tendency to be used as a residual verb in configurations of containment or with gas-like Figures. If the configuration of the Figure and its Ground cannot be seen or at least predicted, the unspecified locative/copular verb on 'it is' is used.

Finally, two verbs share the component 'attachment'. The use of the positional PRV-ǩkrun 'be bound' requires that the Figure is of a ropelike quality, while the positional PRV-çabun 'stick' is used for all other Figures in a configuration that is characterized by attachment.

As can be seen from this summary, the great majority of the positionals in Laz semantically encode information about the shape or some other property of the Figure, while the nature of the Ground only plays a major role in the use of two positionals, namely go-ntun 'be dipped' and PRVnzoy 'be stuck'.

Interestingly, in Laz there is no positional denoting configurations of gas-like Figures lacking support, such as clouds or smoke. In case of clouds resting on a mountain - which by the way is the default behavior for clouds in the mountainous landscape of the Laz region — one may use PRV-zun 'it lies'. For other gas-like Figures such as smoke or smell, the two speakers asked could not give an answer to a "where" question but rather offered utterances such as hakoni zigara dumani "what a lot of cigarette smoke', without using a verb at all, or şura komeçu 'it gives smell'.

The BLC Hierarchy proposed by David Wilkins (see Ameka and Levinson in the introduction to this issue) cannot be confirmed by our data on Laz. For both the positions predicted to occupy the highest (I: piercing, II: firm attachment/encirclement) and the lowest (V: clothing/ adornment, VI: movable objects) endpoints in the hierarchy, appropriate positionals can be found in Laz. The configurations stated for positions III (negative space) and IV (part/whole) in the hierarchy, however, cannot be denoted by positional verbs in Laz. For configurations of negative 
space such as a hole as given in TRPS 18 and 26, Laz speakers preferred the resultative construction while for denoting part/whole configurations such as given in TRPS 61 the possession construction was used.

Received 8 June 2005

University of Cologne

Revised version received

22 January 2007

\section{Appendix. List of abbreviations}

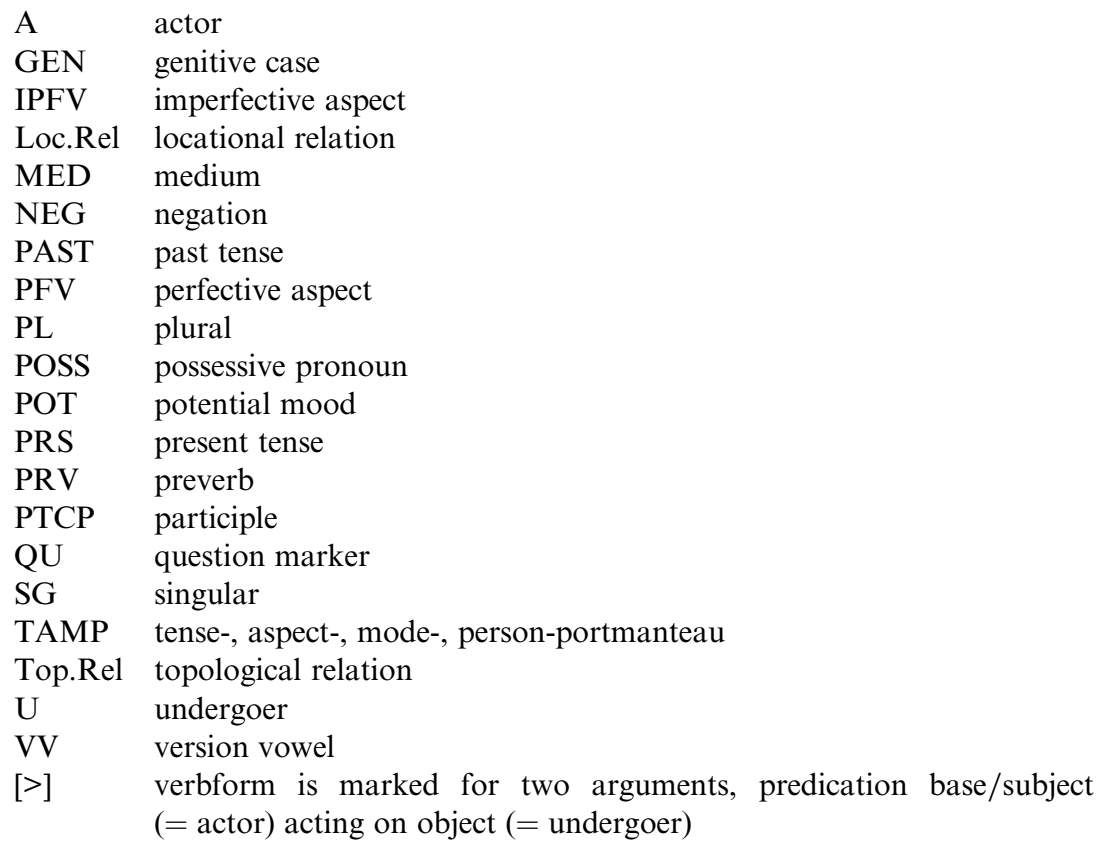

\section{Notes}

* The authors would like to thank Felix Ameka, Eva Schultze-Berndt and two anonymous reviewers for numerous comments on previous versions of this article, and Louise Shuttleworth for brushing up our English. We are also grateful to the patience and helpfulness of the Laz speakers in the region of Ardeşen and in Germany, who have supported our work for several years now. Correspondence address: Silvia Kutscher, Institut für Deutsche Sprache und Literatur, Universität Köln, Albertus-Magnus-Platz, 50923 Köln, Germany. E-mail: silvia.kutscher@uni-koeln.de. 


\section{S. Kutscher and N. S. Genç}

1. Due to the language policy in Turkey, no accurate figures on the numbers of ethnic Laz and the number of speakers of the language can be given. In the region of Ardeșen (i.e., city and surrounding villages) a census in the year 1997 counted 51,192 inhabitants. Approximately $5-10 \%$ of these are ethnic Hemşin. Most of the other inhabitants of Ardeşen and its villages are ethnic Laz (for details, see Kutscher 2001). Only a small number of people belonging to ethnic groups other than Laz or Hemşin live in the region of Ardeşen, most of them being public officials and their families sent to Ardeşen from other regions of the country.

2. Due to some morphosyntactic phenomena in Laz, we give the 3rd person singular present tense form of a verb as citation form instead of the masdar 'verbal noun' that is the citation form used by most Caucasianists.

3. Examples are written in the Lazoğlu/Feurstein alphabet introduced to the Laz community in Turkey in 1984. It deviates from the Caucasianists' transcription in the following graphemes $(\langle\mathrm{Laz}=$ Caucasianist $\rangle):\langle\mathrm{c}=\check{\mathrm{c}}\rangle,\langle\mathrm{c}=\breve{\mathrm{j}}\rangle,\left\langle\breve{\mathrm{k}}=\mathrm{k}^{\prime}\right\rangle,\left\langle\check{\mathrm{p}}=\mathrm{p}^{\prime}\right\rangle$, $\langle s=\check{\mathrm{s}}\rangle,\left\langle\breve{\mathrm{t}}=\mathrm{t}^{\prime}\right\rangle,\langle 3=\mathrm{c}\rangle,\left\langle\breve{3}=\mathrm{c}^{\prime}\right\rangle$.

4. This fieldwork trip was made possible by a grant of the German Society of Endangered Languages (GBS).

5. Elicitation with the two stimuli series is a rather time-consuming method both in elicitation and evaluation of the data. These tools depict Figure-Ground constellations in random order. Each presentation of a stimulus was prompted with the question 'Where is <figure>?' Although the first answer to this question was taken to be the most prominent for denoting the stimulus situation, the consultants had been encouraged to discuss other ways of answering the question. When a consultant used an alternative expression it was checked whether the expression could also apply to already-discussed pictures that in some way seemed to be comparable. Thus, the average time to complete the whole series per language consultant and picture book was two hours. In order not to exhaust the consultant, the tasks were done over several sessions. For comparability of the data, a number of at least three consultants had been recommended in the guidelines of the MPI. The four consultants we could manage to complete the time-consuming task with were all adult women who are fluent in Laz and regularly use Laz in communication with some family members. Two women were in their late thirties, two in their early sixties when they participated in the elicitation sessions. Like all Laz speakers living in Turkey, they are also fluent in Turkish.

6. In Laz, active marking is dependent on the degree of control a participant is conceptualized to have on a state of affairs. A controlling core argument is marked as actor on the predicate, cf. the first person marker $b$ - in (2a). A noncontrolling core argument is marked as undergoer; cf. the first person marker $m$ - in (2b), where the predicate denotes an involuntary physical act. An inactive predicate is indicated by an arrow $(>)$ in the gloss. In predicates with more than one core argument, the arrow is to be read as 'acts upon'.

7. In Laz there is a second type of "where" question, being construed with the possessive verb mizun 'I have' (<figure> so gizun 'where do you have <figure>'), which is used regularly in colloquial speech.

8. In our data, both subtypes of the construction - with and without Figure NP - are found as answers to a where question. Interestingly, when the stimuli books were used, the speakers typically included the Figure NP, whereas in less 'scientific' elicitation situations, such as asking for the location of objects in a kitchen, speakers almost always produced utterances without Figure NP.

9. The most prominent stress is marked by acute accent in the following examples. 
10. For more details on depictive secondary predicates in Laz, see Kutscher and Genç (2005).

11. The verbal roots for 'spill' and 'hang' are homonyms.

12. It seems that etymologically, the root $-r$ - of the positional verb PRV-ren 'human/liquid stands' may be identified as the common Kartvelian root * $r$ - for the copula verb 'be' (cf. Fähnrich and Sardschweladse 1995: 275), which may explain its somewhat odd semantics as expressing the upright position of a human Figure and a topological relation of a liquid Figure to a Ground. But the positional verb deviates from the Laz copula verb bore 'I am' in that the 3rd person singular form is on 's/he/it is' instead of *ren and the copula verb cannot be prefixed by a locational preverb. Hence we classify PRV-ren 'human/liquid stands' as a verbal lexeme on its own.

13. One of the anonymous reviewers points out that the use of -zun here may be related to the fact that the typical way one interacts with a book is by reading it with the book open and laid flat on a table.

14. The version vowel $-i$ - has two allomorphs: with third person undergoers it is represented by $-u-$, otherwise it is represented by $-i-$.

15. The preverb me- exhibits a morphophonological change $m e-\rightarrow n$ - before a version vowel. Thus with the positional $n-o-z u n$ 'it leans', the Ground is always formally integrated into the finite verb by version vowel -o- 'action is directed toward an object'.

16. Note that the verb pxedur 'I live' contains the root -xed- 'sit' from which the causative counterpart of the positional is formed, e.g.,

(i) porça nezi (boya) ce-p-xedum

dress walnut color on-1A-sit:[1>3]SG:PRS

'(lit.: I put walnut juice on my dress.) I stain my dress by putting walnut juice on it.'

17. Fähnrich and Sardschweladse (1995: 47) adduce the meaning 'rip off' for the reconstructed Kartvelian root*-bay- and only mention the meaning 'to shave' for the Laz root $-b y$ - which they see as a cognate of Georgian and Kartvelian -bay-. Bucaklişi and Uzunhasanoğlu (1999: 310) state that in all dialects except Ardeşen, the meaning of the verbal noun obyu is 'to shave' whereas in Ardeşen-Laz it is 'several pieces being spread' (çoğul nesneleri atmak). Note that in Ardeşen-Laz the sense of 'to shave' for the verbal root $-b y$ - does not exist.

18. In Laz, number marking on nominals is nonobligatory except for human referents. NPs unmarked for number may have referents consisting of one or several objects, and quantifiers normally are used with the noun unmarked for number. For details, see Kutscher (2001).

19. This verb is homonymous with the positional PRV-bun 'it hangs', analyzed in Section 5.8 .

\section{References}

Boeder, Winfried (1968). Über die Versionen des georgischen Verbes. Folia Linguistica 2 $(1 / 2), 82-152$.

Bucaklişi, İsmail Avcı and Uzunhasanoğlu, Hasan (1999). Lazuri - Turkuli Nenapuna: Lazca - Türkçe Sözlük. [Laz — Turkish Dictionary]. Istanbul: akyüzyayınc1lık.

Dryer, Matthew S. (1986). Primary objects, secondary objects, and antidative. Language 62, 808-845. 


\section{S. Kutscher and N. S. Genç}

Fähnrich, Heinz and Sardschweladse, Surab (1995). Etymologisches Wörterbuch der Kartwel-Sprachen. Handbuch der Orientalistik: Erste Abteilung: Naher und Mittlerer Osten 24. Leiden: Brill.

Holisky, Dee Ann (1991). Laz. In The Indigenous Languages of the Caucasus: Vol 1: The Kartvelian Languages, Anatolian and Caucasian Studies, Alice C. Harris (ed.), 395-472. Delmar, NY: Caravan.

Kutscher, Silvia (2001). Nomen und nominales Syntagma im Lasischen: Eine deskriptive Analyse des Dialekts von Ardeşen. Lincom Studies in Caucasian Linguistics 17. Munich: Lincom Europa.

- (2003). Raumkonzeptualisierung im lasischen Verb: das System der deiktischen und topologischen Präverbien. In Kaukasische Sprachprobleme, Caucasica Oldenburgensia 1, Winfried Boeder (ed.), 223-246. Oldenburg: Bibliotheks- und Informationssystem der Universität.

— (2007). Kausalität und Argumentrealisierung: Zur Konstruktionsvarianz bei Psychverben in europäischen Sprachen. Unpublished habilitation thesis, University of Cologne.

_; and Genç, N. Sevim (1998). Ardeşen Narrates - Ardeşeni na isinapinenpe: A Collection of Laz Spoken Texts with Glosses and Translations into English, German and Turkish. Languages of the World, Text Collections 14. Munich: Lincom Europa.

-; and Genç, N. Sevim (2005). On depictives in Laz. In Secondary Predication and Adverbial Modification: The Typology of Depictives, Nikolaus P. Himmelmann and Eva Schultze-Berndt (eds.), 235-256. Oxford: Oxford University Press.

Lazoğlu, Fahri and Feurstein,Wolfgang (1984). Lazuri Alfabe: Lazca Alfabe: Entwurf eines lazischen Alphabetes. Parpali 1. Lazuri Carelepe. Laz dili ve kültürü yayınları. Schriftenreihe zur lazischen Kultur. [The Laz Alphabet. Series on Laz Culture 1]. Freiburg (privately printed). 